\title{
AN EXAMINATION OF LEADERSHIP DEVELOPMENT AND OTHER EXPERIENTIAL ACTIVITIES ON STUDENT RESILIENCE AND LEADERSHIP EFFICACY
}

\begin{abstract}
Leadership development programs have become widespread in higher education; over 1500 different programs had been registered with the International Leadership Association as of 2012 (Owen, 2012). Given the prevalence of these programs and the substantial institutional investments they require, examination of their purported impacts is a valid area of investigation. Using the used Multi-Institute Study of Leadership, the current study explored the impact of experiential development programming on two of the instrument's key outcome variables, resilience and self-efficacy. Results found a significant positive relationship between leadership development programs and self-efficacy, but not for resilience. Additional analyses found that other experiential activities (e.g., on-campus jobs, study abroad, etc.) had essentially the same (significant) impact on self-efficacy as did intentionally leadership development ones. Interpretations and implications are discussed.
\end{abstract}

\section{Introduction}

Experiential learning and related activities are critical components of the student collegiate experience today; in fact, decades ago, Cantor (1997) noted that they had already become a core mission for many institutions of higher education to prepare their students to meet the demands of the more complex college environment and world beyond. This influx of intentional experiential education initiatives warrants an investigation into their actual effectiveness in fulfilling the programs' intended objectives. The current study explores the impact of these offerings, with a particular emphasis on leadership-oriented development programs and how they compare to other high-impact experiential activities. More specifically, these experiential programs are compared in terms of each of their relative impacts on two key outcomes that are related to leadership success: self-efficacy and resilience. To the extent that the validity of leadership development and other experiential offerings can be precisely established, the more informed institutions and researchers can be in terms of designing them to prepare students to be effective leaders in the roles they hold and will assume in the future.

\section{Background}

Experiential Education \& Undergraduate Leadership Development Experiences. Twenty years ago, Cantor (1997) noted that experiential education had already become the heart of many institutions of higher education to help meet the demands of the more complex college environment and world that college students faced; at around that time, the Boyer Commission (1998) emphasized the need to continue this movement to design and 
implement innovative models for undergraduate education. Since then, ongoing initiatives driven by organizations such as the Association of American Colleges and Universities' (AAC\&U) Liberal Education and America's Promise (LEAP) have led to a steady increase in student participation in experiential activities and high impact practices (HIPs), both curricular and co-curricular, as institutions recognize the many benefits they bring to students. Briefly defined, HIPs are teaching practices and learning experiences that typically "demand considerable time and effort, facilitate learning outside of the classroom, require meaningful interactions with faculty and other students, encourage collaboration with diverse others, and provide frequent and substantive feedback" (National Survey of Student Engagement, 2017). A growing host of such learning experiences are now offered to college students that extend beyond the classroom, including study abroad, internships, undergraduate research, and service learning, just to name a few. Although not specifically defined as a HIP, formal curricular and co-curricular leadership development programs are additional powerful offerings designed to create transformative growth experiences for students. While these offerings are popular among students, educators and administrators must appropriately ask legitimate questions as to whether these initiatives are indeed fostering the academic and growth opportunities that they hope they are; and specifically in the case of leadership-oriented programs, whether they are facilitating leadership development.

In general, these experiences appear to have a positive impact on students' academic learning as they increase critical thinking (Kuh, 2008; Pascarella \& Blaich, 2013), academic achievement, overall satisfaction with learning (Bauer \& Bennett, 2008) and a desire to learn for the sake of learning (Stone \& Petrick, 2013). In addition, HIPs and experiential programs have been linked to other important aspects of student development. For example, studying abroad has been found to foster students' new perspectives about the world and their place in it (Hadis, 2005), intercultural and personal development (Braskamp, Braskamp, \& Merrill, 2009), and increased self-confidence (Dwyer \& Peters, 2004; O'Neil, 2017). These outcomes are not lost on students, who, in a survey of over 6,000 , most frequently identified their time studying abroad as their most impactful collegiate experience (Paige, Fry, Stallman, Josic, \& John, 2009). From a leadership development perspective, Sroufe, Sivasubramaniam, Ramos, and Saiia (2015) found that study abroad experiences promoted socially responsible leadership in students, which confirmed previous findings (e.g., Parker \& Pascarella, 2013). Students who study abroad also tend to refine their globally competent leadership skills and gain a greater sense of cross-cultural understanding and responsibility (Montgomery \& Arensdorf, 2012).

Other HIP's and experiences have similarly resulted in positive growth in personal and social responsibility, key foundations of the Social Change Model of Leadership Development (Higher Education Research Institute (HERI), 1996) and the Relational Leadership Model (Komives, Lucas, \& McMahon, 2013) that are so popular among leadership educators today. For example, internships, or paraprofessional experiences in the field, not only help students practice linking academic theory to real-world applications, but also enable them to develop a clearer self-concept and value set (Taylor, 1988), adopt a socially responsible orientation towards leadership (Lee, 2010), and enhance their intercultural competence (Kilgo et al., 2015). Service-learning opportunities, which connect the classroom with work in the community, allow for students to directly engage in helping others in real-time scenarios while at the same time having the opportunity to reflect upon course content in the context of service and social engagement. Many studies have established the positive outcomes of service learning, such as socially responsible positive 
leadership (Furco, 1996), global perspective taking (Engberg \& Fox, 2011), community engagement (Simons \& Clearly, 2006), feelings of civic and social responsibility (Einfeld \& Collins 2008; Engberg \& Fox 2011); and intercultural competence (Kilgo et al., 2015), just to name a few. These and other HIPs and experiential collegiate experiences offer students substantial learning opportunities beyond academic content, including the personal and social awareness and skills that are fundamental to effective leadership according to the Social Change Model of Leadership Development (HERI, 1996) and Relational Leadership Model (Komives et al., 2013).

Despite the above programs' connection to the development of leadership competencies, it is quite likely that their designers did not intentionally create them with the term 'leadership' in mind when identifying outcomes. The primary focus of the present investigation is programming specifically and formally designed to foster leadership development. Concurrent with the creation of Multi-Institutional Survey of Leadership (MSL) has been the rise of formal student leadership programs; over 1500 different programs had been registered with the International Leadership Association as of 2012 (Owen, 2012). These leadership programs have been found to have a strong influence on students' socially responsible leadership abilities, especially when compared to students who have had no prior formal leadership training (Dugan \& Komives, 2010). There is substantial research supporting the effectiveness of these leadership development programs for helping students discover their own leadership capacities and enhance their abilities, including collaboration, authenticity, giving and receiving feedback, along with several other critical leadership skills (Eich, 2008). In an intentionally structured program such as an outdoor leadership ropes course, students participate in hands-on activities with peers. Upon completion of activities, a robust debrief as well as feedback and deeper reflection of the purpose of the activities occurs. This type of engaging activity that is created with specific positive leadership outcomes in mind can be highly effective. The nature of the program and its components, as well as the specific institutional environment has a direct impact on students' leadership development (Owen, 2012). Some of these variables include the different types of co-curricular leadership programs available (i.e., outdoor leadership programs and emerging leader programs), the physical existence of a leadership center on campus, and a genuine institutional commitment (e.g., inclusion in an organization's long-term strategic plan) to promote leadership development among its students.

In terms of outcomes, leadership development programs and their related elements are often designed around a competency-based framework the Social Change Model of Leadership (HERI), 1996) and or the Relational Leadership Model (Komives, et al., 2013). Both models highlight the importance of a variety of personal qualities to effective leadership. Two such qualities are self-efficacy and resilience. Of the Social Change Model's ' $7 C$ 's, these are most directly related to 'Individual Values' of consciousness of self, congruence, and commitment as they directly relate to self-management and the persistence towards reaching a goal. In terms of the Relational Leadership Model, self-efficacy and resilience underscore the principles of purposeful and process for the same reason. The following section describes these important characteristics in more detail.

Self-Efficacy. Much of the foundational work on selfefficacy stems from Bandura's (1997) framework, in which he defined the construct as an individual's belief in their ability to reach achievement goals; these beliefs have a critical effect on attitudes, motivations, and behaviors (Bandura, 1997). If an individual is presented with a task that they have never seen before, they will be more likely to be willing to tackle it head-on if they believe that they can succeed in accomplishing it. Domain-specific self-efficacy simply refers to perceived efficacy in a more specific context, such as leadership (Gregersen, Vincent-Höper, \& Nienhaus, 2014). Much research supports the important role of generalized self-efficacy in several areas. If an individual does not ascribe to the belief that they will be able to reach the performance level that 
they determine to be successful, then motivation to continue with these actions when facing obstacles, or even to initially engage in these actions, is significantly lowered (Alessandri, Borgogni, Schaufeli, Caprara, \& Consiglio, 2014). Self-doubt can be overcome with a higher self-efficacy, while also leading to a stronger use of known competencies (Bandura, 1986). Higher self-efficacious individuals tend to exhibit higher work engagement, greater work performance, and have better overall health outcomes and well-being (Alessandri et al., 2014; Gregersen et al., 2014). When a student believes that they will succeed in their classes, they tend to do much better and view their work in healthy way; contrastingly, the self-fulfilling prophecy of anticipated failure in a class often leads to increased stress and decreased performance.

In addition to these extensively studied positive outcomes of strong self-efficacy, negative outcomes associated with a lower self-efficacy have been identified. Individuals with low self-efficacy have a greater likelihood of developing depression, have lower job satisfaction, and are more likely to experience burnout (Gregersen et al., 2014). Moreover, whereas individuals with greater self-efficacy may equate demands to challenges, individuals with lower selfefficacy equate tend to equate demands to threats because of their own uncertainty (Gregersen, et al., 2014). From motivation to performance, the positive outcomes of a higher generalized self-efficacy have robust support.

Leadership self-efficacy refers to one's internal confidence in their skills, knowledge, and abilities to successfully navigate the challenges of leadership (Hannah, Avolio, Luthans, \& Harms, 2008). A myriad of positive associations have been found with leadership self-efficacy, including leader effectiveness, performance, creativity, ethical leadership, transformational leadership, and collective follower efficacy and performance (Cho, Harrist, Steele, \& Murn, 2015). When a student is leading an organization, having confidence in their leadership abilities prevents them from depleting critical cognitive resources on self-doubt and hesitation. Instead, positive energies are channeled towards inspiring and empowering followers, pursuing innovative and challenging initiatives, and generally leading the organization forward with a sense of excitement and vigor. It has also been found that leadership self-efficacy plays a central role in mediating personality differences between leaders and followers, conflicts which can often derail performance and satisfaction if they are not overcome (Cho et al., 2015). In a demanding position, a leader who does not have high confidence in their leadership skills may not feel equipped to lead and inspire a follower who might be more challenging, especially if this follower has serious doubts about their own and the leader's abilities. Having high leadership efficacy can minimize the potential problems of such follower issues.

In another examination of leadership in a university context, Dugan and Komives (2010) found a positive, significant relationship between leadership selfefficacy and socially responsible leadership capacity. Another study showed the strong correlation between leadership self-efficacy and the inclination to even attempt to position oneself in a leadership role (McCormick, Tanguma, \& Lopez-Forment, 2002). Leadership self-efficacy has a clear, essential impact on leadership capacity and other primary leadership behaviors. This is especially applicable to college students, who are going through a formative experience where strong confidence can allow for healthy risk-taking and exploration of different facets within the university setting. Without a belief that they can succeed, college students can very easily evade responsibilities with little accountability, and fail to benefit from significant opportunities for growth.

Resilience. Although there are several definitions of resilience, a generally accepted definition from Connor and Davidson (2003) refers to it as a set of characteristics that allow an individual to overcome threats of adversity, as well as a how successfully one deals and copes with stress. Another conceptual definition is an ability to recover from negative affect and experiences and to gain certain adaptability to varying circumstances (Hu, Zhang, \& Wang, 2015). A positive correlation with positive mental health 
indicators, as well as a negative correlation with negative mental health indicators, is a marked characteristic of resilience (Hu et al., 2015). Studies have also indicated that resilience produces positive emotions; likewise, short-term cognitive effects of positive emotions help generate long-term resilience (Cohn, Fredrickson, Brown, Mikels, \& Conway, 2009). Clearly, resilience is a powerful skill for both defending against adversity and increasing well-being.

The role of resilience in effective leadership has also been investigated, with research suggesting that a positive relationship exists between the two variables (Maulding, Peters, Roberts, Leonard, \& Sparkman, 2012). This relationship manifests itself in an effective leader's ability to adapt to dynamic human behavior and structures while negotiating difficult situations that almost certainly do not proceed in easily anticipated manners (Heifetz \& Linsky, 2002). Within the context of an organization, survival and progress are contingent upon leadership being able to adapt when the initially laid-out map leading to the execution of a vision is at best, uncertain (Mumford, Zaccaro, Harding, Jacobs, \& Fleishman, 2000). Moreover, as a leader, creating a resilient environment for your followers can lead to increased adaptability, well-being, and decreased burnout (Hatler \& Sturgeon, 2013).

Much of the current literature supports resilience as a critical contributor to self-efficacy and leadership efficacy. Bandura (1997) noted the importance of having resilient self-efficacy, which allows individuals to remain persistent and thrive in the face of threatening circumstances. When facing obstacles, leaders tend to exhibit a temporarily lowered leadership self-efficacy; however, with a resilient selfefficacy, individuals are more likely to stay motivated and confident in their abilities to learn and succeed despite having weaker beliefs about their current leadership skills (Machida \& Schaubroeck, 2011). Furthermore, there is a significantly decreased chance of an exponential downward spiral in leadership self-efficacy when the leader has a strong resilient self-efficacy. This research is also supported by a study done by one of the primary MSL researchers on the relationship of resilience and leadership selfefficacy in Asian-American college students, where a strong correlation was found between resilience and leadership self-efficacy development (Kodama, 2014).

High resilience is typically found in exceptional leaders; however, resilience has been thought of as an integral skill for employees and leaders alike in order to truly learn from and think critically about failure and obstacles (King, 2010). Although there is quality research on the role of resilience in leaders, resilience and its relationship with formal leadership development programming does not appear to have been thoroughly explored. Student leaders are facing a variety of obstacles because of the turbulent time college can be for students, both emotionally and in other psychological areas. Striving to lead others during a time of intense self-discovery and potential failure and learning requires strong resilience, and it is imperative to discover what the most valuable methods are for students to succeed in this capacity.

Integration \& Rationale for Hypotheses. As colleges and universities strive to prepare their students for future success, it is important that they evaluate their offerings and identify the optimal methods for fully educating and preparing them during the typical four-year window. Having confidence in one's own leadership abilities and being able to bounce back from failure and obstacles are both desired outcomes of the college experience. Investigating the nature of these relationships offers many fruitful benefits, and a much deeper understanding of the complex interactions between variables and a clearer image of how to best reach maximum student development.

Resilience has been found to be a key tool for effective leaders; as such, it would be logical for effective leadership development programs to develop it in its students. Moreover, increased leadership efficacy is a desired primary outcome for several types of leadership development programming, so the same positive relationship should exist. The present study has a specific focus on experiential programs that are formally defined as 'leadership' by their institution and 
expressly designed to teach it. While an assumption is that other experiential programs (i.e., study abroad, internships, etc.) that are not specifically designated as 'leadership' may still have positive impacts on leadership efficacy and resilience, it is believed that defined leadership programs will have stronger ones given their inherent nature and purpose for which they were created. In reviewing the leadershiporiented activities measured by the MSL, it was determined that some of them were more directly linked to formal academic programming where as others were more experiential in the traditional sense. As such, two categories of leadership programming (academic and experiential) were created to examine the relative and comparable benefits of each.

It was predicted that there would be a significant, positive relationship between both types of formal leadership development programming (academic and experiential) and resilience and leadership efficacy, due to the leadership development skills and experiences specifically emphasized in those programs. It is also hypothesized that the relationships between experiential leadership-based programs and resilience and leadership efficacy will be stronger than the ones between academic leadership programs and these two outcomes. Nonetheless, because these types of leadership programming intentionally focus on developing resilience and leadership efficacy among other leadership qualities as outcomes, it is hypothesized that they will both have stronger relationships with resilience and self-efficacy than will other experiential collegiate activities that do not specifically focus on traditional leadership education. In summary, the formal hypotheses for the current study are as follows:

Hypothesis 1: Both experiential and academic leadership programming will have positive relationships with resilience.

Hypothesis 2: Both experiential and academic leadership programming will have positive relationships with leadership self-efficacy.
Hypotheses 3: Both experiential and academic leadership programming will have stronger positive relationships with resilience than will other experiential collegiate activities.

Hypothesis 4: Both experiential and academic leadership programming will have stronger positive relationships with leadership selfefficacy than will other experiential collegiate activities.

Hypothesis 5: Experiential leadership development programming will have stronger positive relationships with resilience and leadership self-efficacy than will academic leadership development programming.

\section{Method}

The data source for all of the variables in this study was the Multi-Institutional Study of Leadership (MSL, 2012). With an increasing interest in student leadership, the need for a large-scale comprehensive study was clear; the launch of MultiInstitutional Study of Leadership (MSL) in 2006 was developed to address this need. The theoretical foundation for the MSL is the Social Change Model of Leadership Development (HERI, 1996), which was created specifically for college students (Dugan \& Komives, 2007). The MSL survey has been utilized by over 250 colleges and universities worldwide (Dugan, Kodama, \& Correia, 2013). Containing over 400 items, the survey measures dozens of variables including a host of college experiences and student outcomes (MSL Design, 2015).

Participants and Procedure. The MSL in its entirety was distributed online via the Survey Sciences Group, LLC in February 2012, to a mid-sized university in the southeastern United States. A randomly selected student population of 4,000 was generated by the institution's Office of Institutional Research and served as the original potential participant pool. All potential participants were e-mailed three times in one-week intervals, as a reminder to complete the survey. In this personal 
email, basic information about the study, consent, confidentiality, and the survey link itself were shared. Participation was voluntary, and participants did not receive any form of compensation. In addition, anonymity was ensured. MSL raw institutional data was returned to the institution in an Excel spreadsheet and from there imported into SPSS for subsequent analyses.

A total of 2,028 participants completed the survey, which yielded a response rate of $50.7 \%$. Of these, $85.6 \%$ self-identified as White, $7.1 \%$ as Black, $3.9 \%$ as Hispanic, $2.8 \%$ as Asian, .4\% as Indian, and .2\% as Pacific Islander. Of those respondents who completed the MSL, $68.1 \%$ were female and $31.9 \%$ were male; this breakdown generally mirrored the overall gender makeup of the institution, with females in the sample being a few percentage points higher than in the larger population. In terms of class breakdown, 36.3\% were freshmen, $20.9 \%$ sophomores, $21.2 \%$ juniors, and $21.8 \%$ seniors. Participants represented a wide variety of majors, with the top three majors being business (20.6\%), communications $(18.5 \%)$, and social sciences (15.5\%).

\section{Measures.}

Resilience. The ten items for resilience were taken from the MSL and focused specifically on students' resilience since coming to college. Using a Likert-type scale that ranged from 1 (not at all true) to 5 (true nearly all the time), participants were asked to indicate to what extent they agreed with a particular statement as it they applied to them in the last month. An example item is, "I am able to adapt when changes occur." The overall mean for the resilience scale was 39.34, and the standard deviation was 6.14. Cronbach's alpha for the scale was 89 .

Leadership Self-Efficacy. The leadership selfefficacy scale contained four items that were also treated as post-matriculation to college. Using a Likert-type scale that ranged from 1 (not at all confident) to 4 (very confident), participants were asked to indicate how confident they were that they could be successful in a certain activity; one example is "taking initiative to improve something." The mean score of this scale was 12.79, with a standard deviation of 2.40. Cronbach's alpha for the scale was 82 .

Leadership Development Experiences. From the collection of leadership developmentrelated items on the MSL, two separate scales were created for the current study. This was done to note the differences and potential outcomes associated with these distinct categories.

Experiential Leadership Development Programming. The first of these scales, which was labeled 'experiential' included activities that would be described as cocurricular, leadership action-oriented, and generally more focused on the student physically engaging in or practicing leadership or some dimension of it. The MSL items that were assigned to this category were done so through two researchers' rational judgment. The six such leadership development-experiential included attending a leadership retreat, participating in a positional leader training program, living in a leadership learning community, participating in an emerging or new leader program, participating in an outdoor leadership program, or working on peer leadership educator team. Using a Likert-type scale that ranged from 1 (never) to 4 (often), participants rated the extent to which they participated in each of the six engagement activities. A total score for leadership development-experiential was computed by summing each participant's score across these items. The mean for this measure was 10.09, with a standard deviation of 3.40 . 
Academic Leadership Development

Programming. The second leadership development experience scale was created to reflect activities that were, although experiential, less 'handson' and instead reflected more of an academic or traditional course-based learning approach. Three such items were identified and combined to create the leadership development-academic scale for the study. These items included participating in a leadership certificate program, participating in a leadership capstone experience, or taking classes in a leadership studies minor. For each of these activities, participants selected either 0 (not involved) or 1 (involved) to reflect their participation. Overall, 19\% of students completed a leadershipcertificate plan, $12 \%$ a leadership capstone course, and $19 \%$ a leadership minor. These experiences were summed for each student to create a scale score $(M=.49$, S.D.=.82).

\section{Other Collegiate Experiences. A separate} scale was created to assess the extent to which participants engaged in other non-leadershipspecific experiential activities. These items did not comprise a unique scale on the MSL; rather, they were culled by the researchers from different sections of the instrument and that were known to be offered at the participants' institution. Six of the activities were 'traditional' collegiate experiential offerings, and included (percentage of students who participated in them): Community service (55\%), study abroad (39\%), internship/practicum (46\%), living/learning community (13\%), research with mentor (16\%), and living in a learning community (30\%). Two additional activities were included in this scale, off-campus work (13\%) and on-campus work (31\%). Although not typically formally identified as an experiential activity per se, these work items were included based on the rationale that a work setting indeed offered real hands-on experience that could enhance a student's overall growth and development. For each of these eight items, participants simply indicated 'yes' or 'no' as to whether they had engaged in it and a sum was calculated. The mean of the composite for Other Collegiate Experiences measure was 2.41, with a standard deviation of 1.67 .

\section{Analyses and Results}

A series of bivariate correlations were computed to test the hypotheses. The correlation between resilience and leadership efficacy was statistically significant $(r=.47, p<.05)$, suggesting some overlap between the constructs but at the same time providing evidence that they are indeed distinct.

Hypothesis 1 predicted that there would be significant positive relationships between both types of leadership development programming and resilience. To test this, separate bivariate correlations were computed between resilience and each type of leadership programming.

Unexpectedly, no statistically significant relationship was found for resilience with either experiential or academic leadership respectively $(r=.06$ and $r=-.02, n s)$ at the $p<.05$ level. As such, Hypothesis 1 was not supported. Hypothesis 2 anticipated significant, positive relationships between both types of leadership development programming and leadership efficacy. The results indicated a significant positive relationship of $r=.23, p<.05$, between leadership efficacy and experiential leadership development programming. Similarly, a significant positive albeit weaker relationship was found between leadership efficacy and academic leadership development programming $r=.12, p<.05$. As such, Hypothesis 2 was supported.

Hypothesis 3 postulated that formal leadership development programming overall (both academic and experiential) would have stronger relationships with resilience than would other collegiate experiences. Analyses indicated a significant, 
relationship of $r=.13, p<.05$, between other collegiate experiences and resilience. However, neither type of leadership development programming was found to have a statistically significant relationship with resilience. Thus, Hypothesis 3 was not supported.

Hypothesis 4 stated that both types of leadership development programming would have stronger relationships with leadership efficacy than would other collegiate experiences. Results indicated that all three types of experiences did indeed have statistically significant relationships. The correlations relationship between leadership efficacy and academic leadership development programming and experiential leadership development programming were both statistically significant $(r=.12$ and $r=.23$, respectively, $p<.05)$. However, as the relationship between leadership efficacy and other experiences $(r=.22, p<.05)$ was actually higher than leadership efficacy's relationship with academic leadership and not significantly lower than its relationship with experiential leadership, Hypothesis 4 was not supported.

Finally, Hypothesis 5 stated that the relationship between the experiential leadership development programs and resilience and leadership efficacy will be stronger than the ones between academic programs and these two outcomes. As expected, when examining the results regarding leadership efficacy, the experiential leadership development $(r=.23)$ was indeed a better predictor than academic $(r=.12)$. However, it was unexpectedly found that neither leadership programming significantly predicted resilience. Given these mixed results, Hypothesis 5 was partially supported.

While no formal hypotheses were stated about them, all individual leadership activities on the scales and their relationships with resilience and leadership efficacy were examined for exploratory interest; these results are displayed in Table 1.

Table 1

Correlations Between Development Experiences and Resilience and Leadership Efficacy

\begin{tabular}{lcc}
\hline Item & Resilience & Leadership Ef \\
Academic Leadership Development & & $.10^{*}$ \\
Leadership Minor & $-.08^{*}$ & .07 \\
Leadership Capstone Experience & .06 & $.10^{* *}$ \\
Leadership Certificate Program & .00 &
\end{tabular}

Experiential Leadership Development

Leadership Retreat

Positional Leader Training

Emerging/New Leaders Program

Living-Learning Leadership Program

Peer Leadership Educator Team

Outdoor Leadership Program

Other Collegiate Experiences

On-Campus Work

Off-Campus Work

Research with Mentor

Living/Learning Community

Learning Community

Internship/Practicum

Study Abroad

Community Service

$\begin{array}{rc}.07 & .20 * * \\ .06 & .23 * * \\ -.02 & .13 * * \\ -.02 & -.05 \\ .15 * * & .12 * * \\ -.03 & .11 *\end{array}$

\begin{tabular}{ll}
$.05^{*}$ & $.14 * *$ \\
$.10^{* *}$ & $.07 * *$ \\
.04 & $.08 * *$ \\
.04 & .01 \\
.05 & $.05 *$ \\
$.11 * *$ & $.19 * *$ \\
$.05^{*}$ & $.14 * *$ \\
$.05^{*}$ & $.13 *$ \\
\hline
\end{tabular}

Note. $* *$ Indicates significance at the $p<.01$ level; $*$ indicates significance at the $p<.05$ level 
In general, more items were found to be significantly related to leadership efficacy. Among the highest were position leadership training $(r=.23$, $\mathrm{p}<.05)$, leadership retreat $(r=.20)$, and internship/ practicum $(r=.19)$. Other than completing $a$ leadership capstone experience or participating in a living-learning retreat or community, all other activities had significant albeit smaller correlations in the $.05-.15$ range. In terms of resilience, being a member of a peer leadership educator team was the best predictor $(r=.15)$ followed by internship/ practicum $(r=.11)$. Off-campus work $(r=.10)$ was also statistically significant at the $p<.05$ level, as were oncampus work, study abroad, and community service ( $r=.05$ for all). The leadership minor was statistically but negatively related to resilience. However, its small magnitude might suggest random error.

\section{Discussion}

Summary and Interpretation of Findings. Generally speaking, these results suggest that, other engaging collegiate experiences are just as effective at reaching the outcome of leadership efficacy as experiential leadership development programming, and even better than academic leadership development experiences. Furthermore, when it comes to the outcome of resilience, both types of formal leadership development programming appear to be less impactful when compared to the effectiveness of other experiential collegiate activities. This runs counter to the study's hypotheses. From a logical perspective, one would expect that because they are purportedly intentionally designed to specifically enhance leadership skills, these programs would be superior to other experiences.

There are several potential reasons some hypotheses were not supported. First, although most of the other collegiate experiences may not be intentional in reaching certain objectives, most of the experiences may be considered more immersive than some leadership development activities. This has the potential to have a stronger influence on the individual, and give them the ability to have a more reflective, impactful experience. Resilience is an experience-based trait that is perhaps more difficult to develop solely through dialogue and hypotheticals; perhaps more 'real' experiences and the emotions that come with them are required. Things like study abroad or significant community service may thus just naturally have a greater effect on individuals than the more structured leadership development programs. Another possible reason for the lack of relationship between resilience and formal leadership development programming is because resilience is not often cited as a formal goal of many programs (Eich, 2008), and may be viewed more of an indirect objective of programs. In terms of leadership efficacy, it may be the case that leadership programs are just as good as other collegiate experiences simply because leadership efficacy is a broad idea that can be the product of any sort of situation where one's self-esteem is increases as a function of working with others (Hannah et al., 2008).

It is also important to note that experiential leadership development programming overall was found to have much more robust correlations with the two outcomes of interest than academic leadership development programming. This supports Hypothesis 5, and is aligned with much of the body of literature about experiential education and its stronger impact on learning objectives than more static educational mediums (e.g., Cantor, 1997; Kilgo et al., 2015; Kuh, 2008). The items on the experiential leadership development programming scale, such as a retreat or positional leadership training, are much more immersive and hands-on than academic programs like a minor of certificate program, and therefore tend to be more effective in reaching outcomes that heavily rely on experiences like resilience and leadership efficacy.

On one hand, these results are a positive sign for universities as they continue to strive to answer the Boyer Commission's (1998) original call and infuse more HIPs and other experiential learning activities (National Survey of Student Engagement, 
2017). If experiential learning overall is shown to be correlated with higher resilience and leadership efficacy than purely academic methods, and the type of experience does not change that, then students have a multitude of options when working towards reaching these outcomes. A student could study abroad, participate in a leadership retreat, take a service-learning class, engage in an outdoor leadership program; all of these different experiences would help contribute to important leadership outcomes. These various programs allow for students of all different interests, personalities, and collegiate goals to grow and improve themselves, instead of a more limited approach of one-program-fits-all.

However, formal leadership development programs should represent a premier leadership development opportunity at an institution of higher education in terms of strategic, objective-based learning. If institutions truly want to distinguish programs that, by design, purportedly emphasize leadership education from 'other' valuable experiential activities; it is incumbent upon them to demonstrate that their leadership programs do indeed offer something different. Certainly, many experiential programs foster student growth in a variety of ways, including leadership. But in order to more strongly legitimize the place and value of programming that specifically falls under the banner of'leadership,' it would behoove institutions to demonstrate that such programming is distinct from and superior to (or at the very least on par with) other experiential programs in terms of ability to foster leadership-related outcomes. A comprehensive re-evaluation of a program on its objectives and the activities being used to reach those objectives should occur to see if the two are in alignment. Although this should be something that programs do regularly, one question to be asked is whether leadership development programs should be expected to have a stronger effect on resilience/ efficacy than these other experiences - or is that an unfounded assumption? Just because those are variables that have strong correlations with effective leadership, does not mean that the programs being analyzed in the MSL explicitly focused on them as desired outcomes, especially resilience.

Limitations, Implications, and Directions for Future Research. There are several limitations to this study. As a self-report survey, the MSL is susceptive to social desirability and other participant response biases. In particular, as the participants all attended a competitive private liberal arts school, a potential lack of socio-economic diversity is a valid concern. Likewise, the sample was primarily female and white/European American, which although reflective of the institution's student body make-up, still leaves questions about the findings' generalizability to more gender balanced and ethnically diverse student populations. Although the institution is located in the southeast, the majority of students come from the northeast. That said, the regional culture particular to the southeast and to the university itself could also potentially influence acclimatized students' interpretations of their own experiences, resilience, and self-efficacy.

In addition, the data were collected at a single point in time from one institution thereby limiting external validity. While the institution's leadership programming is generally well-regarded within the institution and by others outside of it, this study did not involve a specific assessment of its components. As such, it is possible that the institution's leadership programming was not sufficiently robust to stimulate students' self-efficacy or resilience growth.

As noted above, one implication is that institutions should re-evaluate whether their leadership development programs are sufficiently strong enough to tap into and enhance students' selfefficacy and resilience. Taking into account the significant correlations these variables had with other experiences, perhaps universities might consider borrowing best practices from other programming activities and applying them to leadership development programs. Another idea would be to combine elements of some of these other experiences and create a hybrid sort of 
leadership development program. For instance, creating more service-learning within a leadership program, or even creating a partnership with study abroad programs to amplify that relationship with resilience. One other potential avenue is to add more offerings that force students into obstacles and failure, which are directly related with resilience. Leadership development programs certainly have the potential to offer great value on their own. However, they simply have several potential paths going forward to enhance the student experience. Before a path is decided on, however, it should be determined that resilience is indeed an explicit objective of these programs. To fail, grow, and succeed in the college context and beyond, resilience must be built and refined, and leadership development programs can offer a deep contribution in this area.

Regarding next research steps, a longitudinal study would provide a much deeper exploration of how the different variables interact, and if resilience and leadership efficacy are maintained after these experiences or if there needs to be a continued participation in these types of engaging activities. It would be beneficial to replicate this study, whether in a longitudinal manner or not, at various types of institutions to bolster the external validity. This type of research can also be conducted in an organizational setting to investigate other ways of enhancing resilience and leadership efficacy in an engaging matter. There are also other mediating factors that can be examined, such as different personality traits such as positivity. Positive affect allows for individuals to think and feel in a manner conducive to goal-attainment, in that the individual feels as if they are successfully progressing towards a goal and have sufficient resources (Elliot \& Thrash, 2002). When individuals have a positive outlook on life, they tend to continue to strengthen their resources and relationships, or maintain the same level of positive energy. Variables such as previous educational experiences, personal mental models of leadership, and fields of study could all be potentially interesting mediators as well.
Research concerning the effectiveness of leadership development programming and other collegiate experiences in general must continue to be completed if we want to gain a better understanding of the best ways to reach desirable outcomes for college students. As universities allocate precious resources, staff, and funds into various programs, it is imperative to do this in an informed, researchbased manner. Different types of programs work for different types of students, so it is critical that we are knowledgeable on what tends to work for certain types of students in order to maximize student success. Continued research in the field allows us to recognize the tremendously nuanced relationships between a myriad of factors, furthering our understanding of the ever-dynamic world of higher education and experiential learning. 


\section{References}

Alessandri, G., Borgogni, L., Schaufeli, W., Caprara, G., \& Consiglio, C. (2014). From positive orientation to job performance: The role of work engagement and self-efficacy beliefs. Journal of Happiness Studies, 16(3), 767-788. https://doi.org/10.1007/s10902-014-9533-4

Bandura, A. (1997). Self-efficacy: The exercise of control. New York:W.H. Freeman.

Bandura, A. (1986). Social foundations of thought and action a social cognitive theory. New Jersey: Prentice Hall.

Bauer, K. W., \& Bennett, J. S. (2008). Evaluation of the undergraduate research program at The University of Delaware: A multifaceted design. In R. Taraban \& R. L. Blanton (Eds.), Creating effective undergraduate research programs in science: The transformation from student to scientist. New York, NY: Teachers College Press.

Boyer Commission on Educating Undergraduates in the Research University (1998). Reinventing undergraduate education: A blueprint for America's research universities. Stony Brook, NY: State University of New York. Retrieved from http:// naples.cc.sunysb.edu/Pres/boyer. nsf/673918d46fbf653e852565ec0056ff3e/d955 b61ffddd590a852565ec005717ae/\$FILE/boyer.pdf

Braskamp, L. A., Braskamp, D., \& Merrill, K. (2009). Assessing progress in global learning and development of students with education abroad experiences. Frontiers: The Interdisciplinary Journal of Study Abroad, 18, 101-11. Retrieved at https://files.eric.ed.gov/fulltext/EJ883693.pdf

Cantor J. A. (1997). Experiential learning in higher education: Linking classroom and community. (ERIC Digest No. ED404948). Washington, DC: George Washington University, Graduate School of Education and Human Development.

Cho, Y., Harrist, S., Steele, M., \& Murn, L. (2015). College student motivation to lead in relation to basic psychological need satisfaction and leadership self-efficacy. Journal of College Student Development, 56(1), 32-44. https://doi.org/10.1353/csd.2015.0005

Cohn, M., Fredrickson, B., Brown, S., Mikels, J., \& Conway, A. (2009). Happiness unpacked: Positive emotions increase life satisfaction by building resilience. Emotion, 9, 361-368. https://doi.org/10.1037/a0015952

Connor, K., \& Davidson, J. (2003). Development of a new resilience scale: The Connor-

Davidson Resilience Scale (CD-RISC). Depression and Anxiety, 18(2), 76-82. https://doi.org/10.1002/da.10113

Dugan, J. P., Kodama, C., \& Correia, B. (2013). Multi-Institutional Study of Leadership insight report: Leadership program delivery. College Park, MD: National Clearinghouse for Leadership.

Dugan, J. P., \& Komives, S. R. (2010). Influences on college students' capacities for socially responsible leadership. Journal of College Student Development, 51, 525-549. https://doi.org/10.1353/csd.2010.0009

Dugan, J. P., \& Komives, S. R. (2007). Developing leadership capacity in college students: Findings from a national study. A Report from the Multi-Institutional Study of Leadership. College Park, MD: National Clearinghouse for Leadership Programs. 


\section{References}

Dwyer, M. M. (2004). More is better: The impact of study abroad program duration. Frontiers: The Interdisciplinary Journal of Study Abroad, 10, 151-163. Retrieved at https://files.eric.ed.gov/fulltext/ EJ891454.pdf

Eich, D. (2008). A grounded theory of high-quality leadership programs: Perspectives from student leadership development programs in higher education. Journal of Leadership \& Organizational Studies, 15(2), 176-187. https://doi.org/10.1177/1548051808324099

Einfeld, A., \& Collins, D. (2008). The relationships between service-learning, social justice, multicultural competence, and civic engagement. Journal of College Student Development, 49, 95-109. http://10.1353/ csd.2008.0017

Elliot, A. J., \& Thrash, T. M. (2002). Approach-avoidance motivation in personality: Approach and avoidance temperaments and goals. Journal of Personality and Social Psychology, 82, $804-818$. https://doi. org/10.1037//0022-3514.82.5.804

Engberg, M. E., \& Fox, K. (2011). Exploring the relationship between undergraduate service- learning experiences and global perspective-taking. Journal of Student Affairs Research and Practice, 48(1), 85-105. http://dx.doi.org/10.2202/1949-6605.6192

Furco, A. (1996). Service-learning: a balanced approach to experiential education. Expanding Boundaries: Serving and Learning. Washington, DC: Corporation for National Service, 2-6.

Gregersen, S., Vincent-Höper, S., \& Nienhaus, A. (2014). The relation between leadership and perceived wellbeing: What role does occupational self-efficacy play? Journal of Leadership Studies, 8(2), 6-18. https:// doi.org/10.1002/jls.21318

Hadis, B. F. (2005). Why are they better students when they come back? Determinants of academic focusing gains in the study abroad experience. Frontiers: The Interdisciplinary Journal of Study Abroad, 11, 57-70. Retrieved at https://files.eric.ed.gov/fulltext/EJ891463.pdf

Hannah, S., Avolio, B., Luthans, F., \& Harms, P. (2008). Leadership efficacy: review and future directions. The Leadership Quarterly, 19(6), 669-692. https://doi.org/10.1016/j.leaqua.2008.09.007

Hatler, C., \& Sturgeon, P. (2013). Resilience building: A necessary leadership competence. Nurse Leader, 11, 32-39. https://doi.org/10.1016/j.mnl.2013.05.007

Heifetz, R., \& Linsky, M. (2002). Leadership on the line: Staying alive through the dangers of leading. Boston, Mass.: Harvard Business School Press.

Higher Education Research Institute [HERI]. (1996). A social change model of leadership development: Guidebook version III. College Park, MD: National Clearinghouse for Leadership Programs.

Hu, T., Zhang, D., \& Wang, J. (2015). A meta-analysis of the trait resilience and mental health. Personality and Individual Differences, 76, 18-27. https://doi.org/10.1016/j.paid.2014.11.039

Kilgo, C.A., Ezell Sheets, J. K., \& Ernest T. Pascarella, E.T. (2015). The link between high- impact practices and student learning: Some longitudinal evidence. Higher Education, 69, 509-525. https://doi.org/10.1007/ s10734-014-9788-z 


\section{References}

King, G. A. (2010). Resilience and leadership: The self-management of failure. In M. G. Rothstein \& R. J. Burke (Eds.), New horizons in management. Self-management and leadership development (pp. 361-394). Northampton, MA: Edward Elgar Publishing. https://doi.org/10.4337/9781849805551.00021

Kodama, C. (2014). A structural model of leadership self-efficacy for Asian American students: Examining influences of collective racial esteem and resilience. Dissertations. Paper 1095.

Komives, S.R., Lucas, N., \& McMahon, T.R. (2013). Exploring leadership: For college students who want to make a difference (3rd ed.). San Francisco: Jossey-Bass.

Kuh, G. D. (2008). High-impact educational practices: What they are, who has access to them, and why they matter. Washington, D.C.: Association of American Colleges and Universities.

Lee, G., McGuiggan, R., \& Holland, B. (2010) Balancing student learning and commercial outcomes in the workplace. Higher Education Research and Development, 29(5), 561- 574. https://doi.org/10.1080/0 7294360.2010 .502289

Machida, M., \& Schaubroeck, J. (2011). The role of self-efficacy beliefs in leader development. Journal of Leadership \& Organizational Studies, 18(4), 459-468. https://doi.org/10.1177/1548051811404419

Maulding, W., Peters, G., Roberts, J., Leonard, E., \& Sparkman, L. (2012). Emotional intelligence and resilience as predictors of leadership in school administrators. Journal of Leadership Studies, 5(4), 20-29. https:// doi.org/10.1002/jls.20240

McCormick, M., Tanguma, J., \& López-Forment, A. (2002). Extending self-efficacy theory to leadership. Journal of Leadership Education, 1(2), 34-49. https://doi.org/10.12806/v1/i2/tf1

Montgomery, J., \& Arensdorf, J. (2012). Preparing globally competent leaders through innovative study abroad experiences. Journal of Leadership Studies, 6(1), 64-71. https://doi.org/10.1002/jls.21230

MSL About. (2014). Retrieved December 2, 2014, from http://leadershipstudy.net/about/.

MSL Design. (2014). Retrieved December 2, 2014, from http://leadershipstudy.net/design/.

Multi-Institutional Study of Leadership [MSL]. (2012). MSL 2012 codebook for schools [Data file]. Retrieved from http://www.leadershipstudy.net

Mumford, M., Zaccaro, S., Harding, F., Jacobs, T., \& Fleishman, E. (2000). Leadership skills for a changing world: Solving complex social problems. Leadership Quarterly, 11(1), 11-35. https://doi.org/10.1016/ s1048-9843(99)00041-7

National Survey of Student Engagement (2017). National Survey of Student Data: NSSE 2017 High-Impact Practices. Retrieved from http://nsse.indiana.edu/2017_Institutional_Report/pdf/NSSE17\%20HighImpact\%20Practices\%20(NSSEville\%20State).pdf

O'Neil, C. L. (2017). Study abroad and student-athlete choice (Order No. 10754108). Available from ProQuest Dissertations \& Theses A\&I. (2007302076). Retrieved from https://ezproxy.elon.edu/login?url=https:// search.proquest.com.ezproxy.elon.edu/docview/2007302076?accountid=10730 


\section{References}

Owen, J. E. (2012). Findings from the Multi-Institutional Study of Leadership Institutional Survey: A national report. College Park, MD: National Clearinghouse for Leadership Programs.

Paige, R., Fry, G., Stallman, E., Josić, J., \& Jon, J. (2009). Study abroad for global engagement: The long-term impact of mobility experiences. Intercultural Education, 20, 29-44. https://doi. org/10.1080/14675980903370847

Parker, E. T., \& Pascarella, E.T. (2013, March). Student faculty non classroom interactions and students' moral development over four years of college. Unpublished paper presented at the NASPA Annual Conference, Orlando, FL.

Pascarella, E. T., \& Blaich, C. (2013). Lessons from the Wabash National Study of Liberal Arts Education Change: The Magazine of Higher Learning, 45(2), 6-15. https://doi.org/10.1080/00091383.2013.764257

Peters, M., Flink, I., Boersma, K., \& Linton, S. (2010). Manipulating optimism: Can imagining a best possible self be used to increase positive future expectancies? The Journal of Positive Psychology, 5(3), 204-211. https://doi.org/10.1080/17439761003790963

Simons, L., \& Cleary, B. (2006). The influence of service learning on students' personal and social development. College Teaching, 54(4), 307-319. https://doi.org/10.3200/CTCH.54.4.307-319

Sroufe, R., Sivasubramaniam, N., Ramos, D., \& Saiia, D. (2015). Aligning the PRME: How study abroad nurtures responsible leadership. Journal of Management Education, 39(2), 244-275. https://doi. org/10.1177/1052562914560795

Stone, M., \& Petrick, J. (2013). The educational benefits of travel experiences: A literature review. Journal of Travel Research, 52(6), 731-744. https://doi.org/10.1177/0047287513500588

Taylor, M. (1988). Effects of college internships on individual participants. Journal of Applied Psychology, 73(3), 393-401. https://doi.org/10.1037/0021-9010.73.3.393 